\title{
Natural recovery and restoration in giant panda habitat after the Wenchuan earthquake
}

\author{
Jindong Zhang a,b,c,1, Vanessa Hull ${ }^{\mathrm{b}}$, Jinyan Huang ${ }^{\mathrm{d}}$, Wu Yang ${ }^{\mathrm{b}}$, Shiqiang Zhou ${ }^{\mathrm{d}}$, Weihua Xu ${ }^{\mathrm{a}}$, \\ Yan Huang $^{\mathrm{d}}$, Zhiyun Ouyang ${ }^{\mathrm{a}, *}$, Hemin Zhang $^{\mathrm{d}}$, Jianguo Liu ${ }^{\mathrm{b}, *}$ \\ a State Key Laboratory of Urban and Regional Ecology, Research Center for Eco-Environmental Sciences, Chinese Academy of Sciences, Beijing 100085, China \\ ${ }^{\mathrm{b}}$ Center for Systems Integration and Sustainability, Department of Fisheries and Wildlife, Michigan State University, East Lansing, MI 48823, USA \\ ${ }^{c}$ Institute of Rare Animal and Plants, China West Normal University, Nanchong 637002, China \\ ${ }^{\mathrm{d}}$ China Conservation and Research Center for the Giant Panda (CCRCGP), Wolong Nature Reserve, Sichuan 623006, China
}

\section{A R T I C L E I N F O}

\section{Article history:}

Received 29 October 2013

Received in revised form 20 January 2014

Accepted 21 January 2014

Available online 21 February 2014

\section{Keywords:}

\section{Earthquake}

Restoration

Natural recovery

Giant panda

\begin{abstract}
A B S T R A C T
Natural disasters affect forest ecosystems in profound and complex ways. Artificial restoration projects have been conducted worldwide to repair disaster damage to forests, but the efficacy of such projects in light of naturally occurring recovery processes is rarely evaluated. To fill such an important knowledge gap, we investigated forest recovery and restoration in the world-renowned Wolong Nature Reserve in Sichuan, China after the catastrophic Wenchuan earthquake (magnitude 8.0) in 2008, which caused considerable damage to the forest and habitat of the endangered giant panda. This was the first multi-year field study to document natural recovery of forests in response to this disaster. Forest sampling conducted in panda habitat over a four-year period after the earthquake revealed that natural recovery was rapid, with vegetation covering roughly $70 \%$ of once denuded sites by the fourth sampling year. Vegetation recovery was further improved in sampled artificial restoration sites, which recovered from an average of $30 \%$ vegetation cover to $70 \%$ in only one year. Factors including soil cover and slope were correlated with successful vegetation recovery. New information learned from the multi-year field data provided a finer scale context for understanding the effects of disasters, a novel contribution considering that the majority of previous work has been conducted at the broader scale using remote sensing. Spatial analysis revealed that restoration sites were mainly distributed in areas of suitable slopes and elevations, but a measurable proportion (30-40\%) were located too far from the existing panda distribution area and too close to human settlements. The restoration project has thus far had limited direct effect on giant panda conservation, but has indirect effects on improving forest cover in areas previously affected by human disturbances. This study provides a useful reference for understanding conditions affecting forest recovery, which can inform decision-making surrounding the implementation of forest restoration projects and conservation of endangered species, not only in China but also around the world.
\end{abstract}

(c) 2014 Elsevier B.V. All rights reserved.

\section{Introduction}

Ecosystems around the world are affected by a variety of natural disturbances, such as earthquakes, landslides, hurricanes, tornados, volcanoes, and extreme snow events (Turner et al., 1998; Linderman et al., 2006). Forest ecosystems are particularly affected by such disturbances in a number of ways, including negative effects such as loss of forest cover and declines in tree densities (Liu and Ashton,

\footnotetext{
* Corresponding authors.

E-mail addresses: zhangjd224@163.com (J. Zhang), zyouyang@rcees.ac.cn (Z. Ouyang), liuji@msu.edu (J. Liu).

1 Address: Center for Systems Integration and Sustainability (CSIS), Michigan State University, 1405 S. Harrison Road, Suite 115 Manly Miles Bldg., East Lansing, MI 48823-5243, USA. Tel.: +1 517/432 5028; fax: +1 517/4325066.
}

1999; Hansen et al., 2010; Liu, 2014), and positive effects such as increases in forest diversity as a result of new niches created by periodic disturbance events (Loucks, 1970; White, 1979). While forests have demonstrated remarkable capacity to naturally recover from such disturbances over time (Lin et al., 2005; Millington et al., 2013), humans have also invested tremendous conservation efforts in restoration programs aimed at bolstering or improving such natural recovery (Rodrigues et al., 2009).

Although some forest restoration programs have been conducted, there is considerable debate in the literature as to the necessity and efficacy of such programs (Del Moral and Walker, 2007). Some researchers have pointed out the low chance of success of restoration projects, in addition to significant time and money required for implementation (White and Walker, 1997; 
Ruiz-Jaen and Mitchell Aide, 2005; Cao, 2008; Cao et al., 2010; Liu, 2010). For example, the United States Department of Agriculture (USDA) carried out a restoration project on Mount St. Helens to control erosion caused by volcanic activity (Del Moral and Walker, 2007). The USDA spent over $\$ 2$ million on seeding of exotic plant species and legumes and application of fertilizer, yet erosion was not reduced and conifer regeneration was in fact impeded (Del Moral and Walker, 2007). Despite such examples of restoration programs, few empirical field studies have been done to critically evaluate the design and implementation of such efforts.

Earthquakes are potentially catastrophic events that involve the creation of seismic waves throughout the Earth's crust. Earthquakes cause earth shaking and ground rupture, which can trigger a number of damaging effects such as landslides, treefalls, avalanches, fires, tsunamis, and floods. Forests are potentially affected by all of these effects in numerous ways, the most severe negative effects being the complete destruction of an entire forest ecosystem. Forests have demonstrated the ability to naturally recover from such disturbances via forest succession, but the greater the intensity of disturbances, the longer time required for such recovery to take place (Garwood et al., 1979; Attiwill, 1994). Humans have made efforts to attempt to hasten vegetation recovery in degraded ecosystems (Sayer et al., 2004), one of the main types including areas affected by earthquake-affected areas.

One such earthquake is the Wenchuan earthquake (magnitude 8.0), which struck on May 12, 2008, in Wenchuan County, Sichuan Province, China (Viña et al., 2011). In addition to causing nearly 70,000 human deaths and an estimated 845.1 billion RMB (126 billion USD) in property damage (China Central Television, 2008), the earthquake also destroyed an estimated $1221 \mathrm{~km}^{2}$ of forest, grassland, and wetland ecosystems (Ouyang et al., 2008). Of particular conservation interest is the fact that the earthquake occurred within the limited remaining natural habitat of the giant panda (Ailuropoda melanoleuca), an endangered species and national treasure in China. Approximately $656 \mathrm{~km}^{2}$ (6\%) of giant panda habitat across an area encompassing 19 nature reserves for giant pandas was lost (converted from forest to bare land) to the earthquake, largely by landslides and mudslides (Ouyang et al., 2008).

In response to the Wenchuan earthquake, the Chinese government initiated a recovery plan involving ecological protection and restoration in the disaster area, particularly for the endangered giant panda. Across the giant panda's range, a total of 49 nature reserves (making up approximately $1200 \mathrm{~km}^{2}$ of giant panda habitat) created restoration plans to hasten recovery of damaged giant panda habitat (State Forestry Administration, 2008). While the nearly 160 billion USD recovery effort of human communities and infrastructure in the earthquake affected area (Xinhuanet, 2011) has been extensively researched and documented, little research has been done to evaluate the design, implementation, and success of the recovery efforts geared toward restoration of the natural environment from this disaster.

In this study, we sought to evaluate forest recovery occurring naturally in addition to recovery in response to restoration efforts conducted after this major disturbance event. Here we focus on a 111 million RMB ( $\$ 17$ million USD) forest restoration project carried out in 2010-2011 in Wolong Nature Reserve, a world famous protected area widely regarded as a flagship nature reserve for the protection of giant pandas and their habitat (Deng et al., 2011) and a part of a global biodiversity hotspot (Liu et al., 2003). Our main objective was to investigate patterns of forest recovery after the earthquake and determine whether restoration was more successful than natural recovery alone. We were also interested in knowing whether restoration sites were distributed in areas that were suitable giant panda habitat before the earthquake and how much suitable damaged habitat was found outside of current restoration sites. This study has important implications for studying natural recovery processes and evaluating restoration projects following natural disasters worldwide.

\section{Methods}

\subsection{Study area}

Our study area is located in Wolong Nature Reserve $\left(102^{\circ} 52^{\prime}-\right.$ $103^{\circ} 24^{\prime} \mathrm{E}, 30^{\circ} 45^{\prime}-31^{\circ} 25^{\prime} \mathrm{N}$ ), Sichuan Province, China (Linderman et al., 2005) (Fig. 1). It was established in 1963 as one of China's four earliest giant panda nature reserves (Liu et al., 1999a). In the $1970 \mathrm{~s}$, the area of the reserve was extended to $2000 \mathrm{~km}^{2}$ to accommodate approximately $10 \%$ of the total wild giant panda population (State Forestry Administration, 2006). Aside from giant pandas, there are thousands of plant and other animal species found within the reserve (Li et al., 1992; Tuanmu et al., 2010). Wolong is internationally important because it is also part of UNESCO's Man and Biosphere Reserve network (Liu et al., 1999b).

Wolong is located on the Longmen Mountain fault, a major fault line in southwestern China, and an area that has been subject to frequent tectonic activity since the third century glacial events. Since the 1930s, there have been a total of eight earthquakes above magnitude 7.0 within $200 \mathrm{~km}$ of the epicenter of the Wenchuan earthquake (China Earthquake Networks Center, 2008), including the Ya'an earthquake that occurred $85 \mathrm{~km}$ from Wenchuan in April 2013 (also along the Longmenshan Fault). The distance from the epicenter of the Wenchuan earthquake to Wolong Nature Reserve is less than $10 \mathrm{~km}$, which made it a target for heightened research and management efforts post-earthquake (Wang et al., 2008; Yang et al., 2013). Approximately $56 \mathrm{~km}^{2}$ (7\%) of giant panda habitat in Wolong (total $826 \mathrm{~km}^{2}$ ) was lost (converted from forest to bare land) due to the earthquake (Ouyang et al., 2008).

A forest restoration project was carried out in Wolong in 2010$2011 \mathrm{in}$ an effort to restore roughly $40 \mathrm{~km}^{2}$ of forest in the reserve that was destroyed by the earthquake, mainly due to landslides and mudslides (Sichuan Forestry Development of Science and Technology Industrial Company, 2010). The ambitious plan was estimated to cost 111 million RMB ( $\$ 17$ million USD) and was funded by the investment from the government of the Hong Kong Special Administration Region. The specific objectives of the plan were to (1) restore the ecosystem that was degraded as a result of the earthquake and (2) improve and expand giant panda habitat (Sichuan Forestry Development of Science and Technology Industrial Company, 2010).

The plan laid out four types of target sites for restoration (Fig. 1). The first type was Planting of trees and shrubs in the areas affected by landslides. Planting was conducted during autumn and the main planted species included Cinnamomum longepaniculatum, Picea asperata, Betula albo-sinensis, and Larix mastersiana. The age of planting stock was 1-0 and the density was 1667 /ha. One other species was also planted (Salix cupularis) with an age of planting stock and density of $1-1$ and 2500 /ha, respectively. To improve success, a series of tending measures were carried out, including replanting or repositioning plants as needed and monitoring to prevent fire and pest infestation. The second type of target site was the Seeding site, where seeding of trees and shrubs in the areas affected by landslides was conducted during autumn. The main seeding species included Juglans cathayensis (60 kg/ha), Pinus tabulaeformis (30 kg/ha), B. albo-sinensis (15 kg/ha), Coriaria nepalensis ( $7.5 \mathrm{~kg} / \mathrm{ha}$ ) and oak plants such as Cyclobalanopsis glauca, Fagus longipetiolata, Quercus aquifolioides, and Quercus spinosa (30 kg/ha). Most restoration sites were planted or seeded with mixtures of different species based on the local biophysical conditions and amount of damage received.

The third type of target site was Low Quality Forest Restoration, which included areas unaffected by the earthquake but where 

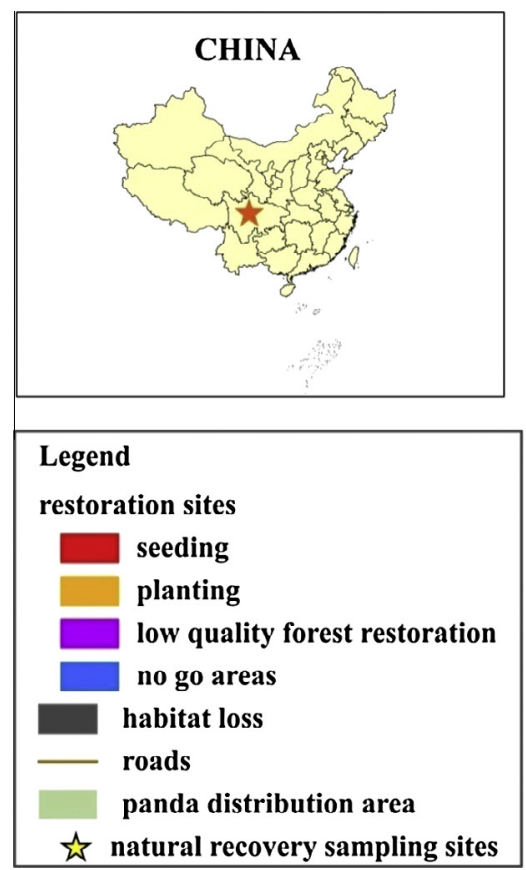

\section{Wolong Nature Reserve}

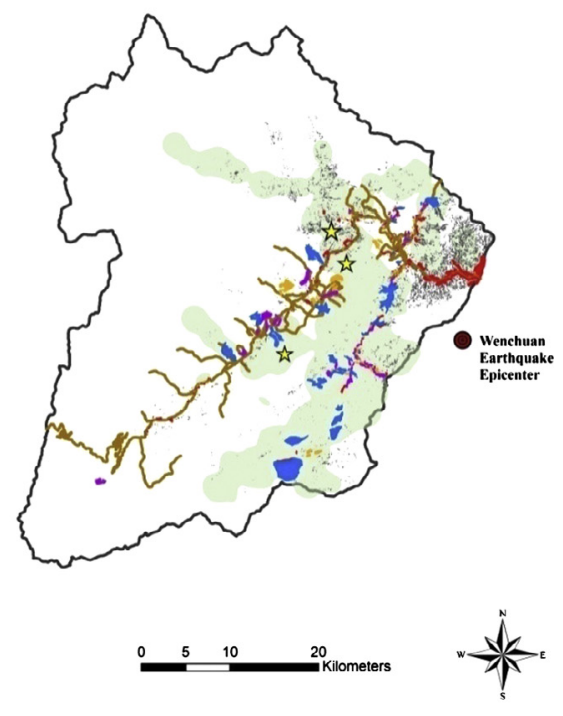

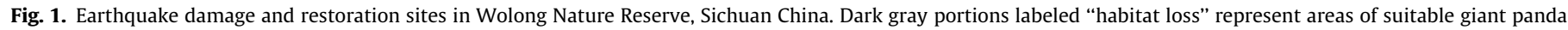


constructing a 95\% kernel $(h=1000 \mathrm{~m})$ on giant panda signs $(n=487$ signs $)$ obtained as part of the 2000-2004 National Giant Panda Census.

forests were otherwise of low quality (low forest cover and woody biomass). Measures undertaken mainly involved planting of trees and bamboo, which was conducted during autumn. Planted bamboo species included Phyllostachys bissetii, Fargesia robusta, Cyperus alternifolius, and Bashania fangiana. All bamboos had 4 branch nodes and a rhizome length of $20-30 \mathrm{~cm}$. The tree species planted was $P$. asperata, which had a height of $2 \mathrm{~m}$. Density of bamboo planted was 833 /ha with the exception of $B$. fangiana, which was 1111 / ha. The density of $P$. asperata was 833 /ha. Bamboo and trees were planted in species mixtures throughout the sites according to local biophysical conditions. Other more intensive measures such as fertilization and irrigation were planned for these sites, however, to date, only planting has taken place in the Low Quality Forest Restoration sites. Planting, Seeding, and Low Quality Forest Restoration made up $12 \%, 21 \%$, and $15 \%$ of the total restoration area, respectively.

These first three types of restoration sites were mainly located in areas demarcated as within the "experimental zone" in the reserve, or areas where human development is allowed (71\%, 56\%, and $59 \%$ of the total area of each restoration type was located in the "experimental zone", respectively) (Sichuan Forestry Development of Science and Technology Industrial Company, 2010). These types of restoration sites were less abundant in the "core zone", where human activities are strictly limited and biodiversity protection is the main focus, and the "buffer zone" which lies between the two zones and softens human impacts occurring in the "experimental" zone.

The fourth type of restoration site consisted of No Go Areas, areas where almost no active restoration activities were planned but human activities were to be forbidden (aside from restoration) in order to ensure natural recovery of the forest. Forbidden activities included cultivation, pasturing, timber harvest, and fuelwood collection (Sichuan Forestry Development of Science and Technology Industrial Company, 2010). No Go Areas made up 52\% of the total restoration area. This type was most abundant in the "core zone" ( $48 \%$ of total) followed by the experimental zone (33\% of total) and buffer zone (19\% of total). In some isolated locations, tree seeds were spread in No Go Areas located in the experimental zone, but the seeding area was small (approximately 8\% of the total No Go Areas).

\subsection{Patterns of vegetation recovery after the earthquake}

We monitored natural recovery of vegetation over a four-year period in 40 earthquake damaged sites (such as landslides and mudflows) across three main focus areas in Wolong (see starred areas in Fig. 1). These focus areas were chosen because they have supported giant pandas over the last 3 decades of giant panda research in the reserve. Damaged sites were randomly chosen from all damaged areas previously encountered during initial field surveys conducted in $2008(n=107)$. At that time, sampling was conducted along 100-200 m wide variable length line transects (500-4000 m long) established via convenient sampling in each focus area (total of 14 transects totaling $35 \mathrm{~km}$ long). We sampled all earthquake damaged sites encountered along these transects (any damage site that had a portion occurring within the transect). We classified a site as damaged if there was a visibly obvious landslide or mudflow and excluded any site receiving only minor damage such as only a fallen tree. Transects were designed to capture the majority of variation in elevation and habitat types in all three focus areas. We determined the boundary of each site by the clearly visible exposure of mineral soil or bedrock and fallen trees due to the earthquake. Average size of all earthquake damaged sites in our sample was $3578 \pm 541 \mathrm{~m}^{2}$ (range 15-180,000 $\mathrm{m}^{2}$ ). Sites were sampled in April 2009, October-November 2010, September 2011, and October-November 2012 (11, 29, 40, and 51 months after the earthquake, respectively).

We also randomly selected 20 earthquake damage sites across the reserve where both Planting and Seeding were conducted from September to October of 2010. Average size of these earthquake damaged sites was $3294 \pm 1189 \mathrm{~m}^{2}$ (range 224-23,000 $\mathrm{m}^{2}$ ). Sites were sampled in September 2011 and November 2012 (3 and 17 months after planting and seeding). Sampling was done in the same way in natural recovery and restoration sites. 
We recorded elevation, slope, aspect, and the length and width (largest two perpendicular distances) of each earthquake damaged site. We also visually estimated the percent of the total damaged area taken up by bare rocks, scree, bare soil, and remnant vegetation (i.e., vegetation that was not destroyed by the earthquake) in each site to the nearest $5 \%$. We counted and recorded the species of all trees, shrubs, and herbs that had grown since the earthquake in the damaged site (hereafter referred to as "recovered vegetation"). The recovered vegetation measures excluded any remnant vegetation present from prior to the earthquake, which consisted mainly of trees. We also visually estimated the percent cover of recovered vegetation present in the site (to the nearest $5 \%$ ) and the overall mean height of recovered vegetation (to the nearest $5 \mathrm{~cm}$ ). Both height and percent cover were visual estimates made by observers spanning the entire earthquake damaged site. We did not record multiple heights for different vegetation layers (e.g. herb layer, shrub layer, tree layer) because the heights of the three did not differ significantly in this early successional stage. We also estimated the percent coverage of trees within the surrounding area of the damaged site (within a $20 \mathrm{~m}$ distance of all of the edges of the damaged site). Visual estimation was conducted by taking an average across estimates from several investigators. We also calculated the distance from each damaged site to the nearest main road using ArcGIS.

We calculated the species richness of trees, shrubs, and herbs in each plot within the earthquake damaged sites using the species richness index (Gleason, 1922):

$D_{G L}=S / \ln (A)$

where $A$ is the area of the earthquake damaged site sampled, and $S$ is the number of different species in the community. This index was chosen because it controls for the variation in surface area among sites. We then calculated the mean species richness of all plots sampled within each earthquake damaged site. We did not calculate species richness data for 2011 in natural recovery sites, as the required data were not collected due to bad weather in this year only.

We compared the mean percent cover of recovered vegetation, mean vegetation height and mean species richness in both natural recovery and restoration sites in a given sampling year to that measured in the previous sampling year using paired $t$ tests. We also compared those same characteristics among natural recovery sites versus human restoration sites in the years in which both sites were sampled (2011 and 2012) using $t$ tests. We also compared all other measured habitat characteristics across the two types of sites using $t$ tests. In all cases, $t$ tests were parametric for normally distributed variables and non-parametric for non-normally distributed variables.

\subsection{Predictors of vegetation recovery after the earthquake}

We performed multiple regression analysis to examine which factors best predicted variation in vegetation recovery in natural recovery sites in 2010 and 2012 . We chose these two years for this analysis because we felt that they captured variation in vegetation recovery over time. Our response variable of interest was percent cover of recovered vegetation growing in the damaged sites since the earthquake in the sampling period. We chose percent cover as opposed to height because there were relatively small changes in height during the early successional stages we sampled and we also believed that percent cover was more accurately estimated using visual estimation. We then performed another multiple regression analysis in the same manner using the combined data from both natural recovery and restoration sites in 2012. In this analysis, we used the variation of recovered vegetation cover from 2011 to 2012 as a dependent variable. We added a dummy variable to represent the type of recovery $(0=$ natural recovery and $1=$ res- toration), which allowed us to test whether restoration had a significant effect on vegetation recovery in comparison to natural recovery while controlling for all other variables. For both analyses, we tested for multicollinearity using the variance inflation factor (VIF) and found no evidence of multicollinearity among variables.

\subsection{Suitability of restoration sites for restoring panda habitat}

We assessed the suitability of the restoration sites for panda habitat by conducting overlap analysis in ArcGIS. We first digitized and georeferenced all restoration sites from paper maps included in the earthquake restoration plan, which we obtained from the reserve administration. We then overlayed the restoration sites on various other layers related to giant panda habitat suitability. Giant pandas avoid steep slopes and prefer moderate elevation and forested areas (Liu et al., 2001). Forest was not considered in our assessment because restoration that could help giant pandas could either involve bolstering existing forest cover or creating new forest cover in areas previously without it. Here all areas with slopes $<45^{\circ}$ and elevations below $3800 \mathrm{~m}$ were labeled as suitable habitat, according to previous suitability indices developed for the species (Liu et al., 1999a). Elevation and slope were obtained from a digital elevation model of Wolong ( $30 \times 30$ m resolution, Viña et al., 2008) obtained from The Advanced Spaceborne Thermal Emission and Reflection Radiometer ( $29 \mathrm{~m} \times 29 \mathrm{~m}$ resolution).

We also considered two spatial variables related to habitat suitability - nearest distance from human settlements and nearest distance from existing panda distribution area. Human establishment layers included roads and local households. Since pandas avoid areas highly impacted by human activity, we labeled any area over $200 \mathrm{~m}$ from a road and $500 \mathrm{~m}$ from a household as suitable. These distances are somewhat arbitrary, but were chosen based on expert opinion about panda avoidance of such impacts (Wang, 2008). Geographic information of roads was obtained from the Wolong administration and household locations were measured by our research team using geographic positioning system (GPS) units. The panda distribution area was estimated by conducting a bivariate normal kernel density estimation (Bailey and Gatrell, 1995) (bandwidth $h=1000 \mathrm{~m}$ ) on all panda signs obtained during the most recent nation-wide giant panda census in 2001 (State Forestry Administration, 2006). We considered any area within 500 meters of the existing panda distribution area as suitable for restoration of panda habitat (since it is not energetically efficient for pandas to travel long distances to visit isolated pockets of habitat).

We summarized the proportion of restoration sites in each habitat suitability class. We then overlayed the restoration sites on a layer of predicted damaged panda habitat and overall forest cover in the reserve that was obtained using remote sensing analysis (Xu et al., 2009) to determine the proportion of damaged habitat that could potentially be restored by the restoration plan. We then calculated the amount of suitable damaged habitat unaccounted for in the restoration plan (according to our aforementioned criteria) and created a map of such areas for further consideration in future restoration efforts.

\section{Results}

\subsection{Patterns of vegetation recovery after the earthquake}

The mean height, percent cover, and species richness of recovered vegetation increased in the earthquake damaged sites undergoing natural recovery during each sampling period conducted after the earthquake (example shown in Plate 1). Mean percent cover of recovered vegetation increased from 0 in 2008 to over $70 \%$ in 2012 (four years after the earthquake) and was significantly 

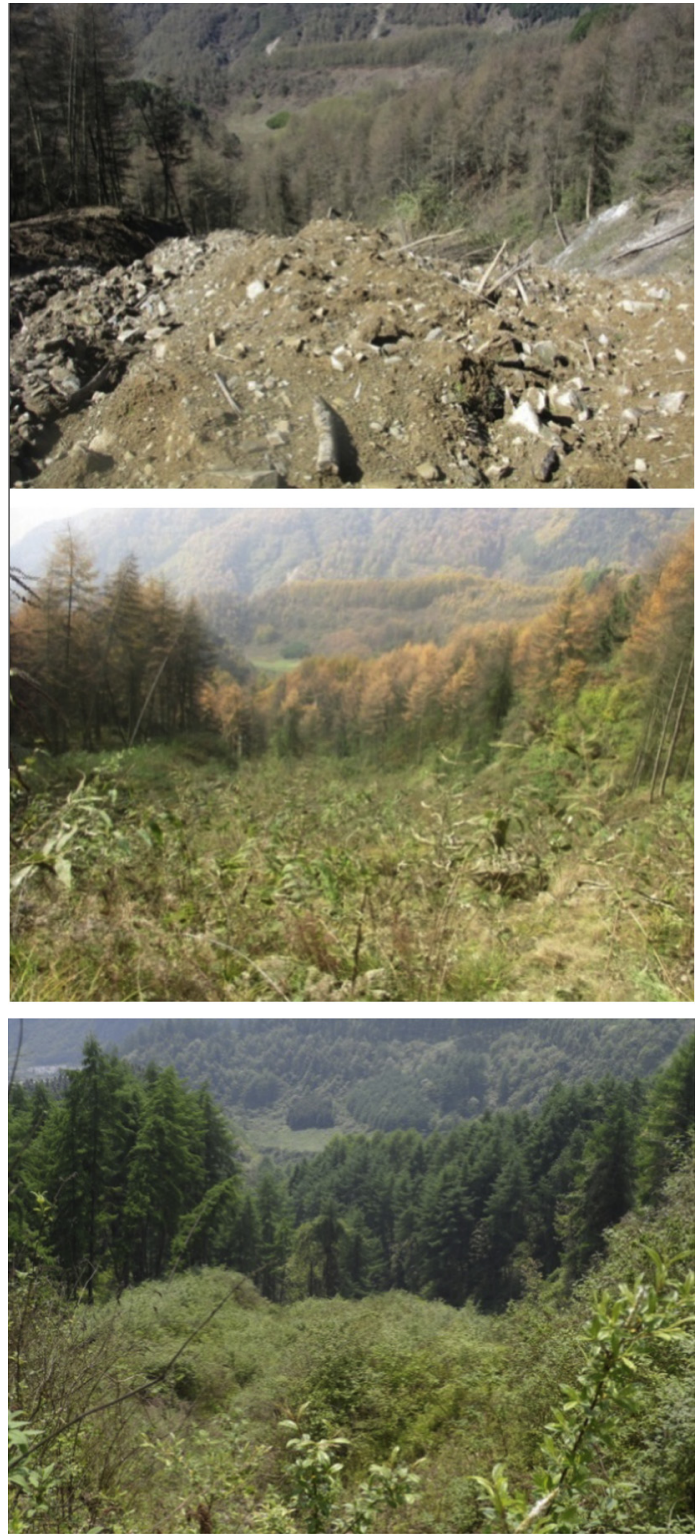

Plate 1. Earthquake damage as a result of a landslide triggered by the May 2008 Wenchuan earthquake in the Huangcaoping focus area in Wolong Nature Reserve, China photographed in April of 2009 (top). Natural vegetation recovery at the same site as of November 2010 (middle) and May 2013 (bottom). Photographs by Jindong Zhang.

higher each year compared to the previous year (Fig. 2a). Over the same four-year period, mean vegetation height increased from 0 to $1 \mathrm{~m}$. With the exception of 2011 , the mean vegetation height was also significantly higher each year compared to the previous year (Fig. 2b). From 2009 to 2012, mean species richness increased from 0.14 to $2.91,0.38$ to 2.43 , and 0.15 to 0.85 for herbs, shrubs, and trees, respectively. The mean species richness of all three layers significantly increased from 2009 to 2010 , but there were no significant differences between 2010 and 2012 (Fig. 2c).

The mean vegetation height and percent cover of recovered vegetation also significantly increased in the restoration sites from 2011 to 2012 (Fig. 2a and b). Mean percent cover of recovered vegetation increased from $33 \%$ to over $70 \%$, while mean vegetation height increased from $36 \mathrm{~cm}$ to $84 \mathrm{~cm}$ from 2011 to 2012 (four years after the earthquake and two years after restoration). The percent increase in mean percent cover and vegetation height from
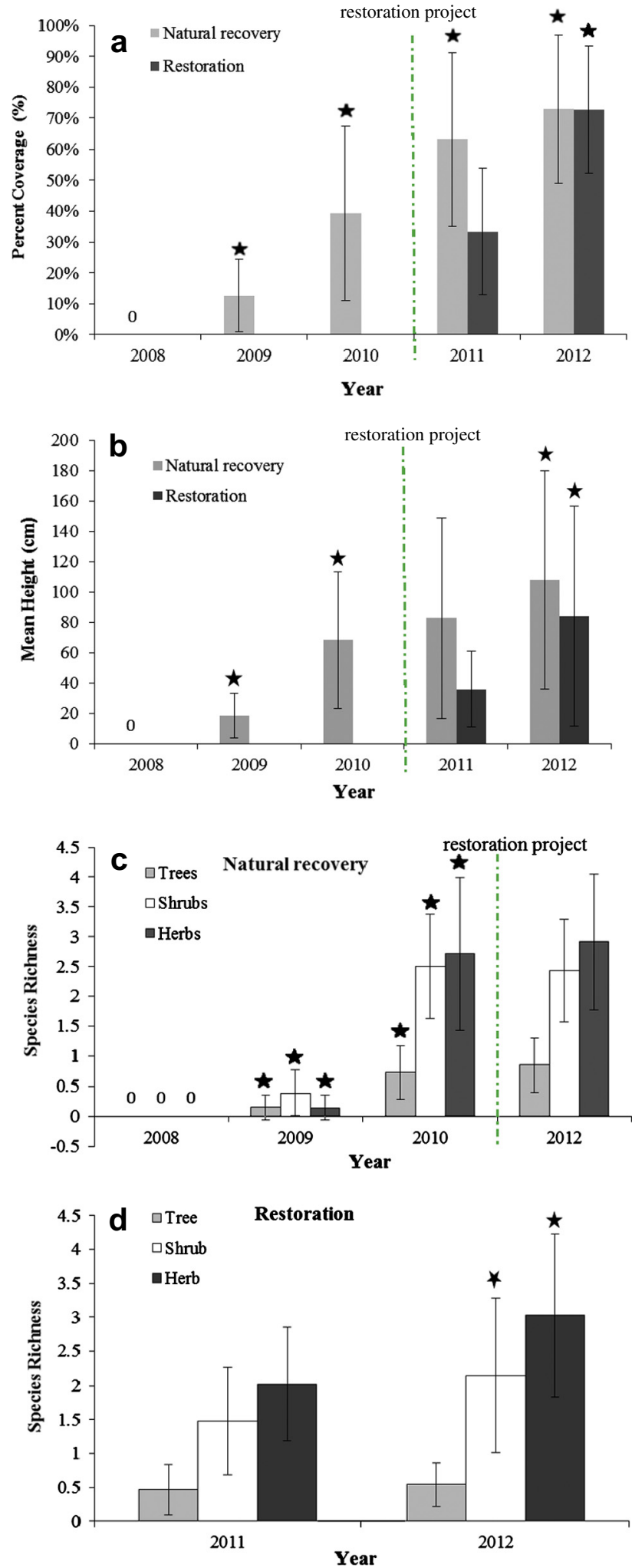

Fig. 2. Mean percent cover (a), and height of recovered vegetation (b) and species richness of trees, shrubs, and herbs in natural recovery ( $n=40$ sites) (c) and restoration ( $n=20)$ sites (d) after the 2008 Wenchuan earthquake in Wolong Nature Reserve China (mean \pm SD). Restoration sites were only sampled in 2011 and 2012; species richness data for natural recovery sites was not available in 2011. Stars indicate significant differences from previous year $(p<0.01)$.

2011 to 2012 was larger in the restoration sites than in the natural recovery sites, since the starting mean percent cover and vegetation height was significantly higher in natural recovery sites than 
human restoration sites in $2011(t=4.209, \mathrm{~d} f=58, p<0.001$; $t=3.953, \mathrm{~d} f=55.15, p<0.001$; Fig. $2 \mathrm{a}$ and $\mathrm{b}$ ) but there was no significant difference between the two site types in 2012 (Fig. 2a and b).

In the restoration sites, mean species richness significantly increased by $50 \%$ (from 2.02 to 3.03 ) and by $45 \%$ (from 1.48 to 2.15) for herbs and shrubs from 2011 to 2012, respectively, while there was no significant difference for trees (Fig. 2d). The mean species richness of trees in naturally recovered sites was significantly higher than that in restoration sites in $2012(t=2.719$, $\mathrm{d} f=58, p<0.05$; Fig. $2 \mathrm{c}$ and $\mathrm{d}$ ), but there was no significant difference in the species richness of herbs and shrubs among the two sites (Fig. 2c and d). Other differences between the two sites included a significantly higher elevation, lower slope, higher surrounding cover of trees, and greater distance to the road in the natural recovery sites compared to the restoration sites (Table 1). Aspect, area of damage and percent of the damaged area taken up by rock, scree, soil, and remnant vegetation did not differ among the two types of sites (Table 1 ).

\subsection{Predictors of vegetation recovery after the earthquake}

In natural recovery sites, percent bare soil and slope were significant predictors of percent cover of recovered vegetation in 2010 (Table 2). Sites with a higher percent bare soil and gentler slope experienced greater recovery. In 2012, the percent bare soil remained as the only significant predictor of percent cover of recovered vegetation (Table 2 ). The combined regression model for both natural recovery and restoration revealed that restoration

\section{Table 1}

Habitat characteristics in sampled earthquake damaged sites in Wolong Nature Reserve that underwent natural recovery $(n=40)$ and restoration $(n=20)$ following the 2008 Wenchuan earthquake. Stars next to the characteristic indicate significant differences between natural recovery and restoration sites at the $p=0.05$ level (as determined using $t$ tests).

\begin{tabular}{lcc}
\hline Characteristic & $\begin{array}{c}\text { Natural recovery } \\
\text { Mean } \pm \text { SD }\end{array}$ & $\begin{array}{c}\text { Restoration } \\
\text { Mean } \pm \text { SD }\end{array}$ \\
\hline Elevation $(\mathrm{m})^{*}$ & $2447 \pm 179$ & $2129 \pm 332$ \\
Slope $\left({ }^{*}\right)^{*}$ & $49 \pm 11$ & $48 \pm 8$ \\
Aspect $\left({ }^{\circ}\right)$ & $76 \pm 44$ & $68 \pm 47$ \\
Area $\left(\log 10 \mathrm{~m}^{2}\right)$ & $2.87 \pm 0.80$ & $3.17 \pm 0.53$ \\
Rock $(\%)$ & $12 \pm 15$ & $13 \pm 11$ \\
Scree $(\%)$ & $20 \pm 19$ & $19 \pm 21$ \\
Bare soil $(\%)$ & $19 \pm 20$ & $27 \pm 15$ \\
Remnant vegetation $(\%)$ & $49 \pm 29$ & $41 \pm 21$ \\
Surrounding tree $(\%)^{*}$ & $53 \pm 24$ & $14 \pm 6$ \\
Distance to road $(\mathrm{m})^{*}$ & $895 \pm 563$ & $120 \pm 100$ \\
\hline
\end{tabular}

had a significant positive effect on vegetation recovery after controlling for other variables (Table 3 ). No other variables were significant predictors of vegetation recovery in this model.

\subsection{Suitability of restoration sites for restoring panda habitat}

All restoration sites were located at suitable elevations (below $3800 \mathrm{~m}$ ) and a large proportion were in areas with suitable slopes $\left(<45^{\circ}, 80-90 \%\right.$ across restoration types, Fig. 3). No Go Areas also were located at suitable distances from human establishments and in proximity to the existing panda distribution. However, a relatively large proportion of Planting, Seeding, and Low Quality Forest Restoration sites (30-40\%) were deemed too close to human establishments and too far from the existing spatial distribution of the panda population.

Overlay analysis revealed that restored sites only overlapped with roughly $7 \%$ of the predicted total damaged panda habitat and $12 \%$ of the total damaged forest cover in Wolong. Our overlay analysis also revealed roughly $21 \mathrm{~km}^{2}$ of panda habitat destroyed in the earthquake that could be targeted for future restoration. These include several distinct pockets of habitat to the north of the main road (Fig. 4).

\section{Discussion}

This is the first study to use multi-year field data to document the success of natural recovery of forests and evaluate the efficacy of a restoration program put in place after the catastrophic Wenchuan

Table 3

Multiple regression models predicting variation of percent coverage of recovered vegetation in natural recovery and restoration sites from 2011 to 2012 ( 3 and 4 years after the Wenchuan earthquake) in Wolong Nature Reserve.

\begin{tabular}{llrl}
\hline Model factors & $\begin{array}{l}\text { Standardized } \\
\text { coefficients } \\
\text { Beta }\end{array}$ & $t$ & $\begin{array}{l}\text { Collinearity } \\
\text { statistics } \\
\text { VIF }\end{array}$ \\
\hline Remnant & -.044 & -.157 & 5.996 \\
$\quad$ vegetation & & & \\
Dummy & .483 & $2.231^{*}$ & 3.607 \\
Soil & -.104 & -.449 & 4.124 \\
Slope & .005 & .030 & 1.891 \\
Scree & .158 & .668 & 4.339 \\
Elevation & -.232 & -1.506 & 1.831 \\
Aspect & .105 & .709 & 1.687 \\
Area (log 10) & -.153 & -1.114 & 1.457 \\
Surrounding trees & .279 & 1.545 & 2.511 \\
Distance to road & -.228 & -1.015 & 3.891 \\
\hline
\end{tabular}

Adjusted $R^{2}=0.235$.

* $p<0.05$.

Table 2

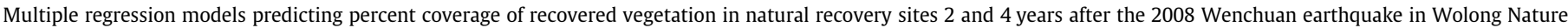
Reserve.

\begin{tabular}{|c|c|c|c|c|c|c|}
\hline \multirow[t]{2}{*}{ Model factors } & \multicolumn{3}{|l|}{2010} & \multicolumn{3}{|l|}{2012} \\
\hline & $\begin{array}{l}\text { Standardized coefficients } \\
\text { Beta }\end{array}$ & $t$ & $\begin{array}{l}\text { Collinearity Statistics } \\
\text { VIF }\end{array}$ & $\begin{array}{l}\text { Standardized coefficients } \\
\text { Beta }\end{array}$ & $t$ & $\begin{array}{l}\text { Collinearity Statistics } \\
\text { VIF }\end{array}$ \\
\hline Soil & $0.682^{* *}$ & 5.058 & 1.311 & $0.605^{* *}$ & 4.04 & 1.332 \\
\hline Remnant vegetation & -0.117 & -0.892 & 1.253 & 0.022 & 0.153 & 1.253 \\
\hline Elevation & -0.112 & -0.814 & 1.366 & -.133 & -.821 & 1.567 \\
\hline Aspect & 0.026 & 0.208 & 1.141 & 0.115 & 0.715 & 1.543 \\
\hline Slope & $-0.304^{*}$ & -2.229 & 1.345 & -0.125 & -0.827 & 1.368 \\
\hline Area & 0.198 & 1.432 & 1.374 & 0.11 & 0.735 & 1.331 \\
\hline Surrounding trees & -0.184 & -1.489 & 1.102 & 0.067 & 0.446 & 1.325 \\
\hline
\end{tabular}

2008-2010: Adjusted $R^{2}=0.473,2008-2012$ : Adjusted $R^{2}=0.361$.

* $p<0.05$.

*** $p<0.01$. 


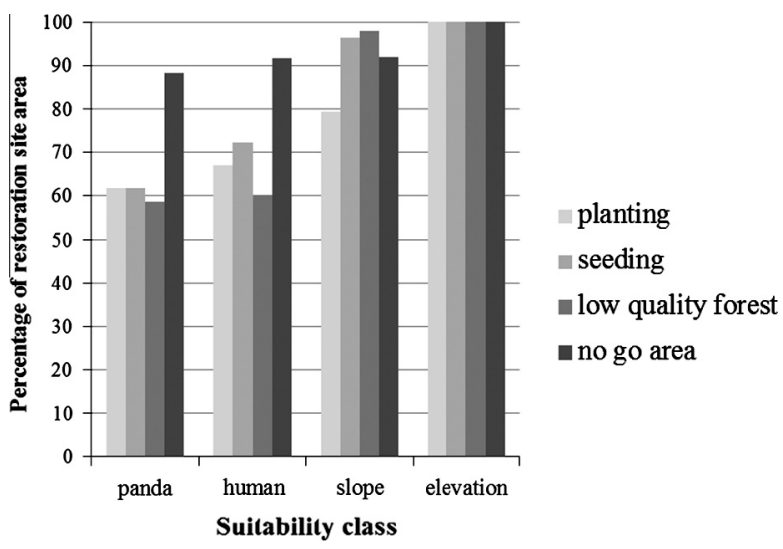

Fig. 3. Percentage of the total area of four types of earthquake restoration sites distributed across different giant panda habitat suitability classes in Wolong Nature Reserve, Sichuan, China. Suitability classes include within $500 \mathrm{~m}$ of the existing giant panda distribution in the reserve (panda), at least $200 \mathrm{~m}$ away from roads and $500 \mathrm{~m}$ from households (human), less than $45^{\circ}$ slope (slope), and less than $3800 \mathrm{~m}$ elevation (elevation).

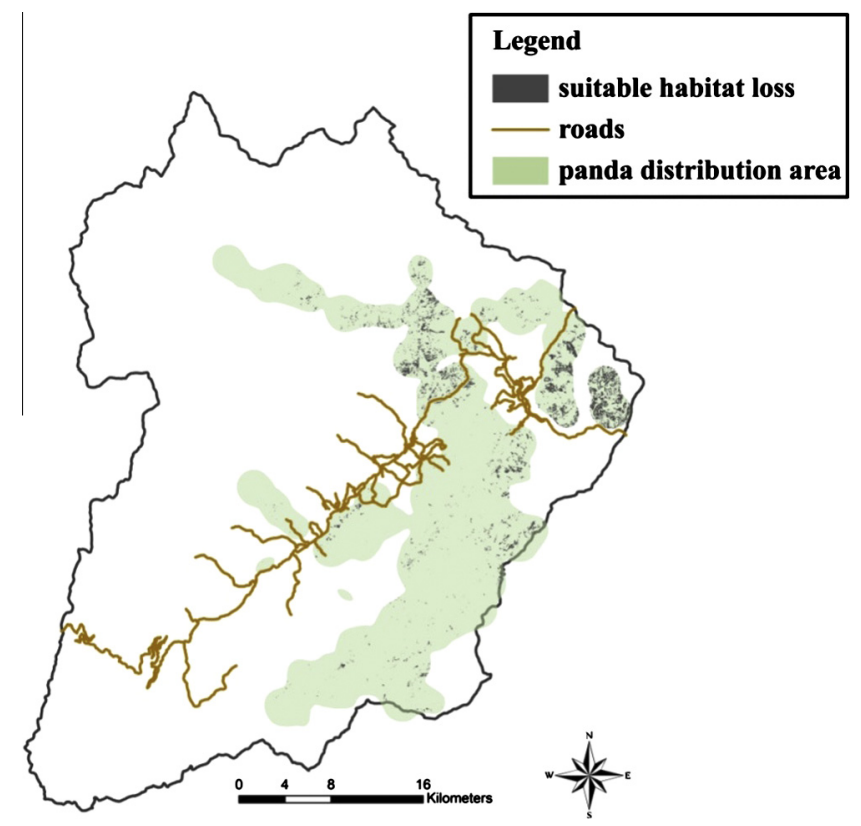

Fig. 4. Panda habitat damaged in the Wenchuan earthquake in Wolong Nature Reserve not included in the existing restoration plan that may be considered for future restoration. Habitat damage was obtained by Xu et al. (2009) (forest that had been lost in the earthquake) but was reduced to reflect only areas that matched our suitability classes (shown in Fig. 3) and areas outside of existing restoration sites.

earthquake in Sichuan, China. The results are significant with respect to contributing to a broad understanding of the remarkable ability of forests to recover from disturbance, a phenomena that has long been observed (Halpern, 1988) but is dynamic and often unpredictable in a world with increasingly frequent and intense natural disasters. The results also are noteworthy in contributing to an understanding of the resilience of the forest ecosystem in Wolong Nature Reserve, a forest that supports some of the highest biodiversity anywhere on the earth, but one that is understudied, particularly with respect to field studies conducted around disturbance events. Our study corroborates previous remote sensing analyses that have documented forest cover re-growth at the coarse $\left(250 \mathrm{~m}^{2}\right)$ scale in Wolong after the earthquake (Liu et al., 2010), but also provides finer scale context to document marked increases in observed forest cover, tree height, and species richness postdisaster.

Our study also showed significant effects of restoration efforts on forest recovery. The fact that in 2011 ( 3 months after restoration), restoration sites initially had significantly lower vegetation cover and height than natural recovery sites likely reflects their overall poorer habitat quality (e.g. less surrounding vegetation and steeper slopes than natural recovery sites). The fact that restoration helped overcome these shortcomings by allowing the vegetation to recover faster than in the natural recovery sites indicates that the restoration project helped to recover damaged forests in Wolong. Previous studies from around the world documenting the effectiveness of seed sources in facilitating vegetation recovery in disturbed areas have shown mixed results, with some demonstrating its importance (Purata, 1986) and others not finding significant effects (Hupp, 1983). Our results suggest that restoration efforts such as planting and seeding may provide a measurable added benefit for damaged forests in Wolong. Part of the success of the restoration may be attributed to the fact that the species chosen for restoration were native trees and shrubs, species which were well-adapted to the local climate and soil and also those which do not pose a risk of invasiveness in the future.

This study also provided insights on habitat characteristics that can allow for higher vegetation recovery after earthquakes. The significant positive effect of percent bare soil in explaining vegetation recovery in our models corroborates previous studies in other landslide sites around the world that have also shown similar results with respect to soil and may be attributed to the soil properties such as organic composition and moisture, which play important roles in forest succession (Lin et al., 2005; Velázquez and Gómez-Sal, 2008).That said, in light of our demonstrated importance of soil for vegetation recovery, the plans for more intensive restoration efforts such as irrigation and fertilization of soils in the Low Quality Forest Restoration sites may be worthwhile, but further research is needed.

The importance of gentle slopes that we found in one of our models has also previously been shown to be advantageous for forest recovery in landslides. This is in part due to the superior structural support such areas provide for vegetation growth, in addition to the fact that gently sloped areas generally have a higher concentration of organic soils and seed sources than steep areas in early succession (Guariguata, 1990). However, the fact that slope was only significant in our 2010 model and not in 2012 or in the combined model of natural recovery and restoration suggests that it may not be a significant factor under all conditions. One possible explanation is that plant root systems are underdeveloped in the initial stages of recovery, which causes significant water and nutrient loss in steep slope conditions, an effect which may be later muted as roots mature.

Our spatial overlay analysis reveals that although the restoration sites were distributed across largely suitable slopes and elevations, there was a relatively high proportion of them close to existing human establishments, which makes them both less desirable for pandas and also vulnerable to future human disturbances. However, one benefit of the location of the restoration sites is that they help protect human establishments from future landslides, which may indirectly benefit panda habitat, considering that humans may be less likely to seek out additional resources in panda habitat if their needs for human settlements are being adequately met.

No Go Areas outlined in the restoration plan are in the best spatial locations to contribute to panda conservation in the reserve. However, their utility is questionable, considering that they effectively serve the same purpose as other already existing policies in the reserve, namely the zoning policy which already labels core zones as essentially "no go" areas. While No Go Areas overlap 
significantly with the existing core zone ( $48 \%$ of all No Go Area), even the value of the additional No Go Areas outside of the core zone may also be small, considering the challenges of monitoring such delineations on the ground when it is impossible to draw strict boundary lines along the rough terrain in the reserve to regulate human activities (Hull et al., 2011).

The fact that a measurable proportion of restoration sites were over $500 \mathrm{~m}$ outside of the existing panda distribution, combined with the fact that a large area of damaged suitable habitat lies outside of the restoration sites, suggests that they may have limited value for pandas in the current design. Indeed, the proportion of panda habitat that remains damaged inside the current panda distribution suggests that more could potentially be done in other areas farther from the human establishments. Consideration of such spatial relationships is important, as pandas have tight energy budgets and will not travel long distances outside of their normal ranges to use small pockets of habitat because it is not energetically efficient for them to do so (Schaller et al., 1985).

\section{Management implications}

Considering the documented success of natural recovery in panda habitat, we believe that natural recovery will continue to occur on its own within the reserve in response to this natural disaster in the future. In fact, the ecosystem may be adapted to periodic earthquake events that occur along this major fault line. On the other hand, the apparent success of restoration in accelerating the recovery of the forest in areas where human disturbance had removed vegetation does have value. This program, although costly, can contribute to other restoration efforts that have been ongoing in this reserve involving reforestation of areas impacted by human disturbances, including the Grain to Green Program (GTGP) (Liu and Diamond, 2005). Although restoration of such disturbed areas close to human establishments may not directly increase panda habitat, it does provide income earning opportunities to local people, protect human settlements from landslides, and can indirectly reduce human disturbance to pandas and their habitat by providing a forest buffer.

Anthropogenic disturbances historically and currently pose a much greater threat to giant panda habitat than natural ones (Schaller, 1987; Liu et al., 2001; Bearer et al., 2008). Ongoing threats include fuelwood collection, medicinal herb collection, and livestock grazing (State Forestry Administration, 2006). These threats may have even been magnified after the earthquake. The tremendous loss of life, property, and employment opportunities from the earthquake was catastrophic for the livelihoods of local residents, which may have contributed to an increase in participation in illegal activities to generate much needed income, such as poaching and grazing animals in the forest (Yang et al., 2013). The government sought to address the need for providing income earning opportunities for local communities in the postearthquake period via the employment opportunities of the restoration plan, which was critically important in such a vulnerable period for local people. We suggest that the local government should expand this line of thinking into long-term planning to find ways to improve the local economy that do not threaten biodiversity or even enhance the provision of ecosystem services.

The actions taken in Wolong have great significance in the broader context of panda conservation and post-earthquake recovery in China because Wolong is a flagship nature reserve that guides management at broader scales. Our observations in this study can thus help guide restoration in the 49 nature reserves (covering $1200 \mathrm{~km}^{2}$ ) that have restoration projects in progress (State Forestry Administration, 2008). Our findings suggest that restoration may have some positive effects if conducted in areas with suitable slopes and adequate soils, particularly in areas without adequate surrounding vegetation present. Restoration of areas once being good panda habitat that have not been able to naturally recover from destruction by human impacts in the past may also be possible. In fact, several studies point to a need for restoration of corridors to connect the highly fragmented panda habitat at range-wide scales (Xu et al., 2006; Viña et al., 2010). Considering the aforementioned challenges of meeting human livelihoods, we recommend combining restoration of the habitat with employment opportunities to help recover the local economy.

Worldwide, natural disasters have profound effects on forest ecosystems. Humans have invested considerable resources into accelerating the recovery of landscapes damaged by natural disasters using advanced restoration programs. Our study contributes to the ongoing dialogue on restoration by demonstrating the importance of taking into account natural recovery processes and the initial condition of damaged sites. Our results suggest that forest restoration may be best suited for areas of good habitat conditions, such as with gentler slopes and more soil. In addition, our study highlights the fact that the design of restoration programs should concurrently consider both wildlife habitat distribution and human activities in order to ensure that restoration is best able to meet intended goals sustainably in a telecoupled world (Liu et al., 2013).

\section{Acknowledgements}

We thank the Wolong Nature Reserve Administration and the staff at the China Center for Research and Conservation of the Giant Panda (CCRCGP) for their support. We thank Rengui Li, Dian Liu, Shumin Fan, Wenbin Yang, and Hong Yang for carrying out field work. We acknowledge the following sources of funding: National Science Foundation (NSF), the National Aeronautics and Space Administration (NASA), the Michigan State University Distinguished Fellowship Program, the William W. and Evelyn M. Taylor International Engagement Program, the National Natural Science Foundation of China (40901289), the open fund of the State Key Laboratory of Urban and Regional Ecology, Research Center for Eco-Environmental Sciences, Chinese Academy of Sciences (SKLURE2008-1), and the Giant Panda International Collaboration Fund (SD0631; SD1113), Sichuan Provincial Department of Education (12ZB259), and Sichuan Provincial Department of Science and Technology (2008SZ0115).

\section{References}

Attiwill, P.M., 1994. The disturbance of forest ecosystems: the ecological basis for conservative management. For. Ecol. Manage. 63, 247-300.

Bailey, T.C., Gatrell, A.C., 1995. Interactive Spatial Data Analysis. Prentice Hall, Harlow, England.

Bearer, S., Linderman, M., Huang, J., An, L., He, G., Liu, J., 2008. Effects of fuelwood collection and timber harvesting on giant panda habitat use. Biol. Conserv. 141, 385-393.

Cao, S., 2008. Why large-scale afforestation efforts in China have failed to solve the desertification problem. Environ. Sci. Technol. 42, 1826-1831.

Cao, S., Tian, T., Chen, L., Dong, X., Yu, X., Wang, G., 2010. Damage caused to the environment by reforestation policies in arid and semi-arid areas of China. Ambio 39, 279-283.

China Central Television, 2008. News report. CCTV. <http://news.cctv.com/china/ 20081008/103396.shtml> (in Chinese).

China Earthquake Networks Center, 2008. Historic earthquakes within $200 \mathrm{~km}$ of Wenchuan since 1933. <http://www.csi.ac.cn/sichuan/sichuan080512 his.htm> (in Chinese).

Del Moral, R., Walker, L.R., 2007. Environmental Disasters, Natural Recovery and Human Responses. Cambridge University Press.

Deng, D., Yan, W., Huang, X., Liu, X., Mu, C., 2011. Ecological restoration after Wenchuan earthquake in Sichuan province: implementation and review. J. Sichuan For. Sci. Technol. 5, 56-61 (in Chinese).

Garwood, N.C., Janos, D.P., Brokaw, N., 1979. Earthquake-caused landslides: a major disturbance to tropical forests. Science (New York, NY) 205, 997.

Gleason, H.A., 1922. On the relation between species and area. Ecology 3, 158-162. 
Guariguata, M.R., 1990. Landslide disturbance and forest regeneration in the upper Luquillo Mountains of Puerto Rico. J. Ecol., 814-832.

Halpern, C.B., 1988. Early successional pathways and the resistance and resilience of forest communities. Ecology 69, 1703-1715.

Hansen, M.C., Stehman, S.V., Potapov, P.V., 2010. Quantification of global gross forest cover loss. Proc. Natl. Acad. Sci. 107, 8650-8655.

Hull, V., Xu, W., Liu, W., Zhou, S., Vina, A., Zhang, J., Tuanmu, M., Huang, J., Linderman, M., Chen, X., Huang, Y., Ouyang, Z., Zhang, H., Liu, J., 2011. Evaluating the efficacy of zoning designations for protected area management. Biol. Conserv. 144, 3028-3037.

Hupp, C.R., 1983. Seedling establishment on a landslide site. Castanea, 89-98.

Li, C., Zhou, S., Xiao, D., Chen, Z., Tian, Z., 1992. A general description of Wolong Nature Reserve. In: Wolong Nature Reserve, S.N.C. (Ed.), The animal and plant resources and protection of Wolong Nature Reserve. Sichuan Publishing House of Science and Technology, Chengdu, China, pp. 313-325 (in Chinese).

Lin, W.T., Chou, W.C., Lin, C.Y., Huang, P.H., Tsai, J.S., 2005. Vegetation recovery monitoring and assessment at landslides caused by earthquake in Central Taiwan. For. Ecol. Manage. 210, 55-66.

Linderman, M.A., An, L., Bearer, S., He, G., Ouyang, Z., Liu, J., 2005. Modeling the spatio-temporal dynamics and interactions of households, landscapes, and giant panda habitat. Ecol. Modell. 183, 47-65.

Linderman, M.A., An, L., Bearer, S., He, G., Ouyang, Z., Liu, J., 2006. Interactive effects of natural and human disturbances on vegetation dynamics across landscapes. Ecol. Appl. 16, 452-463.

Liu, J., 2010. China's road to sustainability. Science 328, 50.

Liu, J., 2014. Forest sustainability in China and implications for a telecoupled world. Asia and the Pacific Policy Studies.

Liu, J., Diamond, J., 2005. China's environment in a globalizing world. Nature 435, 1179-1186.

Liu, J., Ashton, P.S., 1999. Simulating effects of landscape context and timber harvest on tree species diversity. Ecol. Appl. 9, 186-201.

Liu, J., Daily, G.C., Ehrlich, P.R., Luck, G.W., 2003. Effects of household dynamics on resource consumption and biodiversity. Nature 421, 530-533.

Liu, J., Linderman, M., Ouyang, Z., An, L., Yang, J., Zhang, H., 2001. Ecological degradation in protected areas: the case of Wolong Nature Reserve for giant pandas. Science 292, 98-101.

Liu, J., Hull, V., Batistella, M., DeFries, R., Dietz, T., Fu, F., Hertel, T.W., Izaurralde, R.C., Lambin, E.F., Li, S., Martinelli, L.A., McConnell, W.J., Moran, E.F., Naylor, R., Ouyang, Z., Polenske, K.R., Reenberg, A., Rocha, G.M., Simmons, C.S., Verberg, P.H., Vitousek, P.M., Zhang, F., Zhu, C., 2013. Framing sustainability in a telecoupled world. Ecol. Soc. 18, 26.

Liu, J., Ouyang, Z., Taylor, W.W., Groop, R., Tan, K., Zhang, H., 1999a. A framework for evaluating the effects of human factors on wildlife habitat: the case of giant pandas. Conserv. Biol. 13, 1360-1370.

Liu, J., Ouyang, Z., Tan, Y., Yang, J., Zhang, H., 1999b. Changes in human population structure: implications for biodiversity conservation. Popul. Environ. 21, 4558.

Liu, Y., Liu, R., Ge, Q., 2010. Evaluating the vegetation destruction and recovery of Wenchuan earthquake using MODIS data. Nat. Hazards 54, 851-862.

Loucks, O.L., 1970. Evolution of diversity, efficiency, and community stability. American Zool. 10, 17-25.

Millington, J.D., Walters, M.B., Matonis, M.S., Liu, J., 2013. Filling the gap: a compositional gap regeneration model for managed northern hardwood forests. Ecol. Modell. 253, 17-27.

Ouyang, Z., Xu, W., Wang, X., Wang, W., Dong, R., Zheng, H., Li, D., Li, Z., Zhang, H., Zhuang, C., 2008. Impact assessment of Wenchuan earthquake on ecosystems. Acta Ecol. Sin. 28, 5801-5809 (in Chinese).
Purata, S.E., 1986. Floristic and structural changes during old-field succession in the Mexican tropics in relation to site history and species availability. J. Trop. Ecol. 2, 257-276.

Rodrigues, R.R., Lima, R.A.F., Gandolfi, S., Nave, A.G., 2009. On the restoration of high diversity forests: 30 years of experience in the Brazilian Atlantic Forest. Biol. Conserv. 142, 1242-1251.

Ruiz-Jaen, M.C., Mitchell Aide, T., 2005. Restoration success: how is it being measured? Restor. Ecol. 13, 569-577.

Sayer, J., Chokkalingam, U., Poulsen, J., 2004. The restoration of forest biodiversity and ecological values. For. Ecol. Manage. 201, 3-11.

Schaller, G., 1987. Bamboo shortage not only cause of panda decline. Nature 327, 562.

Schaller, G.B., Hu, J., Pan, W., Zhu, J., 1985. The Giant Pandas of Wolong. University of Chicago Press, Chicago, Illinois, USA.

Sichuan Forestry Development of Science and Technology Industrial Company, 2010. Wolong Nature Reserve's plan for ecological restoration of vegetation after the Wenchuan earthquake (in Chinese).

State Forestry Administration, 2006. The Third National Survey Report on the Giant Panda in China. Science Publishing House, Beijing, China (in Chinese).

State Forestry Administration, 2008. Special planning of ecological reconstruction after Wenchuan earthquake. <http://www.forestry.gov.cn/ZhuantiAction.do? dispatch $=$ content\&name=kzjz\&id=118062> (accessed 01.30.13) (in Chinese).

Tuanmu, M.-N., Viña, A., Bearer, S., Xu, W., Ouyang, Z., Zhang, H., Liu, J., 2010. Mapping understory vegetation using phenological characteristics derived from remotely sensed data. Rem. Sens. Environ. 114, 1833-1844.

Turner, M.G., Baker, W.L., Peterson, C.J., Peet, R.K., 1998. Factors influencing succession: lessons from large, infrequent natural disturbances. Ecosystems 1, 511-523.

Velázquez, E., Gómez-Sal, A., 2008. Landslide early succession in a neotropical dry forest. Plant Ecol. 199, 295-308.

Viña, A., Bearer, S., Zhang, H., Ouyang, Z., Liu, J., 2008. Evaluating MODIS data for mapping wildlife habitat distribution. Rem. Sens. Environ. 112, 2160-2169.

Viña, A., Tuanmu, M.-N., Xu, W., Li, Y., Ouyang, Z., DeFries, R., Liu, J., 2010. Rangewide analysis of wildlife habitat: implications for conservation. Biol. Conserv. 143, 1960-1969.

Viña, A., Chen, X., McConnell, W.J., Liu, W., Xu, W., Ouyang, Z., Zhang, H., Liu, J., 2011. Effects of natural disasters on conservation policies: the case of the 2008 Wenchuan Earthquake, China. AMBIO: A J. Human Environ. 40 (3), 274-284.

Wang, D., Li, S., Sun, S., Wang, H., Chen, A., Li, J., Lu, Z., 2008. Turning earthquake disaster into long-term benefits for the panda. Conserv. Biol. 22, 1356-1360.

Wang, X., 2008. The Impact of Human Disturbance on Giant Panda Habitat in the Minshan Mountains. Chinese Academy of Sciences, Beijing (in Chinese).

White, P.S., 1979. Pattern, process, and natural disturbance in vegetation. Bot. Rev. 45, 229-299.

White, P.S., Walker, J.L., 1997. Approximating nature's variation: selecting and using reference information in restoration ecology. Restor. Ecol. 5, 338-349.

Xinhuanet, 2011. Wenjiabao: A report about re-construction after the Wenchuan earthquake. <http://news.xinhuanet.com/politics/2011-05/10/c_121396310. $\mathrm{htm}>$ (accessed 01.30.13) (in Chinese).

Xu, W., Dong, R., Wang, X., Ouyang, Z., Li, Z., Xiao, Y., Zhang, J., 2009. Impact of China's May 12 earthquake on giant panda habitat in Wenchuan county. J. Appl. Rem. Sens. 3, 1-10.

Xu, W., Ouyang, Z., Vina, A., Zheng, H., Liu, J., Xiao, Y., 2006. Designing a conservation plan for protecting the habitat for giant pandas in the Qionglai mountain range, China. Diversity Distrib. 12, 610-619.

Yang, W., Dietz, T., Kramer, D.B., Chen, X., Liu, J., 2013. Going beyond the Millennium Ecosystem Assessment: an index system of human well-being. PloS One 8, e64582. 